\title{
ASSESSMENT
}

\section{Academic and Professional Preparedness: Outcomes of Undergraduate Research in the Humanities, Arts, and Social Sciences}

\author{
Kelly Kistner, Erin M. Sparck, University of California, Los Angeles \\ Amy Liu, Hannah Whang Sayson, University of California, Los Angeles \\ Marc Levis-Fitzgerald, Whitney Arnold, University of California, Los Angeles
}

\begin{abstract}
As many studies on undergraduate research outcomes are focused on STEM fields, the widely variable experiences in the humanities, arts, and social sciences are less known and harder to study. This article assesses outcomes among students who pursued faculty-mentored research in those fields and concurrently participated in programs administered through UCLA's Undergraduate Research Center for the Humanities, Arts, and Social Sciences (URC-HASS). As program participants receive support to help counterbalance discrepancies across departments and mentors, they also form a distinct sample group useful for statistical analysis. Compared to a quasi-control group of nonresearch students, the research students reported statistically significant better outcomes on average in attaining several of the skills sought by today's employers, thus demonstrating the potential benefits of undergraduate research in these disciplines.
\end{abstract}

Keywords: arts, humanities, independent study, social sciences, student outcomes, undergraduate research

doi: $10.18833 /$ spur/4/4/1

The likely outcomes and benefits of undergraduate research experiences have been studied and are well-documented in this journal and elsewhere. However, the majority of such assessments are based on undergraduate research programs and experiences in STEM fields (Haeger et al. 2020). Knowledge of student research experiences in the humanities, arts, and social sciences is considerably more limited, and, as Haeger and colleagues (2020) assert, "desperately needed" (67). This relative scarcity cannot be attributed to a lack of undergraduate research undertaken in humanities, arts, and social science fields, nor to a lack of interest in the topic. It can be attributed to, in part, the relative lack of large funded programs requiring centralized administration and assessment compared to STEM fields, as well as wide variations in how an undergraduate research experience might be structured in humanities, arts, and social science fields. (For the purposes of this study and in line with the structure of UCLA's academic divisions and corresponding units, humanities, arts, and social sciences are defined here as encompassing psychology but not psychobiology or cognitive science.) Given more limited instances of centralized program coordination and the inherent variation in how the undergraduate research experience is structured across the humanities, arts, and social sciences, it is simply more challenging to study the research experience on the whole in humanities, arts, and social science fields in comparison to STEMbased research experiences.

Considering these challenges, it is not surprising that in existing studies of undergraduate research outcomes in the humanities, arts, and social sciences, the observations are often based on student experiences in programs with centralized assessment and specific diversity and career objectives such as the McNair Research Scholars or Mellon Mays Undergraduate Fellows programs (Nnadozie, Ishiyama, and Chon 2001; Prenovitz et al. 2016). In other instances, the knowledge comes largely from studies of relatively small programs or a small number of students, often limited to a particular program or department, or where the research structure more closely mirrors traditional STEM experiences (e.g., Hartmann 1990; Kremer and Bringle 1990; Ishiyama 2002; Landrum and Nelsen 
2002; Rand 2016). Even where humanities, arts, and social science research opportunities are addressed as a part of cross-disciplinary data sets (e.g., Craney et al. 2011; Lopatto 2006), the observations are often drawn from specialized summer programs or laboratory-like settings.

Although the previously mentioned studies add valuably to knowledge of undergraduate research, a more generalizable assessment of undergraduate research experiences in non-STEM disciplines is needed-an assessment that encompasses typical research experience in these areas but that is admittedly hard to typify because the experiences are so variable. This variability is owing in large part to the tendency for students in these areas to design and carry out their own independent projects but also the differing levels of support, including both formalized and informal guidance and instruction, that these students may receive from their faculty mentors and departments. Although some departments may offer more-or-less structured capstone or honors thesis programs, in many cases the research experience is fully constructed on a case-by-case basis as an agreement between an individual mentor and a student pursuing a self-directed project. The end goals and objectives of the research pursuit can be just as individual, and, in the absence of large, sponsored programs more common in STEM, there is typically a lack of centralized coordination and evaluation for undergraduate research pursuits. Therefore, it is difficult to gather a sufficient and diverse enough sample of students to study the generalized impact of research in these areas.

Despite these differences, undergraduate research in the humanities, arts, and social sciences is not at all uncommon. This makes the relative lack of knowledge on its outcomes in comparison to STEM fields even more problematic. It cannot be assumed that gains from undergraduate research in humanities, arts, and social science fields are the same as those from STEM fields. A holistic view of the specific benefits for students majoring in a humanities, arts, or social science field is needed, as well as knowledge of whether student outcomes in those fields differ for those with mentored research experience versus those without it. Without this knowledge, higher education institutions and departments are unable to make the most informed decisions on whether or how to devote more resources and rewards behind expanding and improving undergraduate research opportunities in these fields.

This is critical knowledge at a time when non-STEM fields face declining enrollment and severe cuts (Hayot 2018), and employers are expressing dissatisfaction with the skills of college graduates. A 2012 employer survey conducted by the Chronicle of Higher Education and American Public Media's Marketplace found that, "[w]hen it comes to the skills most needed by employers, job candidates are lacking most in written and oral communication skills, adaptability and managing multiple priorities, and making decisions and problem solving" (Chronicle of Higher Education 2012, 12). The 2019 Job Outlook Survey by the National Association of Colleges and Employers (NACE) found similar employer priorities (NACE 2019).

Despite the inherent challenges of drawing inferences from quite disparate experiences, the authors believe they are uniquely positioned to build this knowledge base and bring more attention to the outcomes of undergraduate research in the humanities, arts, and social sciences. Since 1998, UCLA has offered a dedicated center for undergraduates pursuing research in the humanities, arts, and social sciences. Its Undergraduate Research Center for the Humanities, Arts, and Social Sciences provides centralized administration of, and support for, undergraduate research experiences across the humanities, arts, social sciences, and psychology. Moreover, its Undergraduate Research Scholars Program (URSP) and Undergraduate Research Fellows Program (URFP) provide scholarships; supplemental resources; and dedicated support for students undertaking research and creative projects in the humanities, arts, or social sciences.

Students who have participated in the URSP and/or URFP programs make up a sampling frame that is well-suited to assessing the impact of undergraduate research in the humanities, arts, or social sciences within the contexts in which they normally occur. For one, the programs are open campus-wide to any undergraduate interested in or already pursuing research or a creative project mentored by a faculty mentor. Thus, there is wide variation in the fields, methodologies, mentors, class standings, and career goals and interests of the student participants. This more accurately reflects the total diversity of research opportunities and student researchers across campus than an assessment of any one single program offered by a department or external sponsor. Furthermore, although URSP and URFP participants have access to additional support and resources, the programs are not fully standardized and not as immersive as programs with specific end-goals such as the McNair Research Scholars and Mellon Mays Undergraduate Fellowship programs. Instead, the URSP and URFP equalize resources and provide a consistent baseline of support to student researchers who may not have the benefits of a highly engaged mentor or formal departmental program. For instance, students in URSP and URFP have the option to arrange individual meetings with the URC-HASS program directors (who have faculty appointments) and PhD students who work for the center as mentors. The program directors and graduate student mentors review students' work in progress and provide guidance on research processes, communication, and preparation for careers or further education. Center staff also develop and coordinate optional workshops for students in these programs. URSP students are additionally required to 
present their work in progress during a URSP colloquium, and URFP students attend a seminar on research skills and professional development that runs one academic quarter. Students in both programs are expected to present their work at UCLA's annual Undergraduate Research Week. Thus, these students are sampled because the real and considerable variation can be captured that is inherent across undergraduate student experiences in humanities, arts, or social sciences while minimizing the range of variation in support offered to these undergraduate researchers.

\section{Method}

To assess the impact of the research experience for these students, two analyses were conducted of (1) entry and exit surveys completed by the program participants and (2) UCLA's Senior Survey completed by program participants. The latter were compared against Senior Survey responses from a control group of similar students graduating without the research experience. Thus, the analyses encompassed both an internal program assessment instrument with direct reference to the URC-HASS research programs (entry/exit surveys), as well as a broader assessment of student outcomes that situated student research experiences within the context of their larger UCLA experiences (Senior Survey).

The first instrument, composed of the entry and exit surveys, was administered by the URC-HASS to only URCHASS program participants and included both closed- and open-ended questions about the students' self-assessed skill competencies and the program experience. Of interest for the present study were students' responses to each of the eight skill competency questions within both the entry and exit surveys, in which students were asked to rate on a Likert scale their proficiencies in a series of researchrelated skills. The scale contained five options ranging from "none" to "expert." The paired entry and exit survey responses were analyzed for 199 students in URC-HASS programs between 2014 and 2018.

As the entry and exit surveys prompted students within the research programs to think about the programs and thus may be prone to response biases, analysis of the second instrument, the UCLA Senior Survey, allowed for comparison of URC-HASS program participants' responses to a control group of UCLA students who did not participate in research. Each spring, all fourth-year students at UCLA are asked to complete a survey on both their academic and co-curricular experiences at the university, including information about their overall experience at UCLA, academic experience, personal development, campus life, and postgraduation plans.

Drawing on the methods of DeAngelo and Hasson (2009) and Toven-Lindsey and colleagues (2015), a fuzzy case control matching procedure was used to match 156
URC-HASS program participants' Senior Survey responses (78.4 percent of the 199 program participants from 2014 to 2018 ) to 142 other UCLA students who completed the Senior Survey at the conclusion of the same academic years but who did not participate in research. The students were matched based on year admitted to UCLA, gender, transfer status, academic division, Pell Grant recipient status, ethnicity, California residence status, and GPA. Thirty-two potential questions of interest from two different sections of UCLA's Senior Survey were identified for exploration. In questions from one section, students self-reported their academic and personal development as impacted by their UCLA experiences using a Likert scale with four options ranging from "none" to "very much." In the other set of questions, students reported their self-perception of traits compared with average students of the same age using a Likert scale with five options ranging from the "lowest 10 percent" to the "highest 10 percent."

Each question from the URC-HASS entry and exit surveys and the UCLA Senior Survey was labeled as relating to one of the NACE career readiness competencies that employers rated as essential for new hires (see Table 1). NACE has identified eight competencies, ordered by employer rating of importance from the 2019 Job Outlook Survey (NACE 2019): critical thinking/problem solving, teamwork/collaboration, professionalism/work ethic, oral/written communication, digital technology, leadership, career management, and global/intercultural fluency.

\section{Results}

Using paired sample $t$-tests for the entry and exit survey data and independent samples $t$-tests for the Senior Survey data, the authors identified statistically significant differences $(p<0.05)$ in the self-report data for students in research programs in three of the four most critical areas identified and ranked by NACE: critical thinking/problem solving (first), professionalism/work ethic (third), and oral/written communication (fourth).

All eight of the skill competencies questions from the URC-HASS entry and exit surveys presented in Table 2 (developing a research question, finding sources, conducting a literature review, analyzing and synthesizing information, developing an argument, presenting findings/arguments in writing, presenting findings/arguments orally, and writing a research proposal) showed significant changes reflecting self-reported growth from the time of entering the program to completing the program ( $p<$ $0.001)$. There were seven questions from the Senior Survey, presented in Table 3, where URC-HASS program participants self-reported greater proficiencies in skills relative to the matched control group $(p<0.05)$. Four of those questions related to academic and personal development 
TABLE 1. Measures of NACE Competencies

\begin{tabular}{|c|c|c|}
\hline NACE competency & $\begin{array}{l}\text { URC-HASS entry and } \\
\text { exit survey outcomes }\end{array}$ & $\begin{array}{l}\text { Senior Survey } \\
\text { skill self-rating }\end{array}$ \\
\hline $\begin{array}{l}\text { Critical thinking/problem } \\
\text { solving (CT/PS) }\end{array}$ & $\begin{array}{l}\text { (1) Developing a research } \\
\text { question } \\
\text { (2) Finding sources } \\
\text { (3) Conducting a literature } \\
\text { review } \\
\text { (4) Analyzing and synthesizing } \\
\text { information } \\
\text { (5) Developing an argument }\end{array}$ & $\begin{array}{l}\text { (1) Ability to make informed } \\
\text { decisions that require } \\
\text { analyzing information } \\
\text { from many perspectives } \\
\text { (2) Critical thinking } \\
\text { (3) Academic ability }\end{array}$ \\
\hline $\begin{array}{l}\text { Professionalism/work ethic } \\
\text { (P/WE) }\end{array}$ & N/A & $\begin{array}{l}\text { (1) Desire for lifelong learning } \\
\text { (2) Drive to achieve }\end{array}$ \\
\hline $\begin{array}{l}\text { Oral/written communication } \\
(\mathrm{O} / \mathrm{WC})\end{array}$ & $\begin{array}{l}\text { (1) Presenting my findings/ } \\
\text { arguments in writing } \\
\text { (2) Presenting my findings/ } \\
\text { arguments orally } \\
\text { (3) Writing a research proposal }\end{array}$ & $\begin{array}{l}\text { (1) Ability to communicate } \\
\text { effectively in writing } \\
\text { (2) Writing ability }\end{array}$ \\
\hline
\end{tabular}

Note $:$ NACE = National Association of Colleges and Employers. URC-HASS = UCLA's Undergraduate

Research Center for the Humanities, Arts, and Social Sciences

due to their UCLA experiences (ability to make informed decisions that require analyzing information from many perspectives, critical thinking, desire for lifelong learning, and ability to communicate effectively in writing), whereas the other three questions (academic ability, drive to achieve, and writing ability) reflected students' thoughts about themselves relative to their peers.

These statistically significant outcomes are all the more remarkable given the following:

1. the inherent variation within the sample of undergraduate researchers in URC-HASS programs responding to the Senior Survey and mirrored within the sample of non-research respondents (across GPA; major; gender; Pell Grant-recipient status; race/ethnicity; US residency status; and, if applicable, their admittance as a first-year or transfer student),

2. the limited range of the response variables from 1 to 4 or 1 to 5 on whole-number Likert scales, and

3. the design of the Senior Survey, which does not prompt students to reflect on their research program but rather asks them to reflect on themselves and their overall UCLA experience.

It also is noteworthy that the entry and exit surveys for the URSP and URFP programs show students' distinct gains in skills over the course of the research experience, which may be reflected in the Senior Survey sample of research students reporting higher measures on critical thinking, writing, and decision-making. Those are all tangible skills cultivated through experience and training and in high demand in the labor market.

\section{Discussion and Future Directions}

Although it is not surprising that the students in research programs reported gains in research-related proficiencies according to internal program assessments (the entry and exit surveys), it does show a process of skill development occurring over the course of the research program. More remarkably, the findings from the Senior Survey suggest that, in addition to the research skill gains noted above, the research students developed more broadly transferrable skills in decision-making and critical thinking, along with a professional work ethic and desire for continued learning. Given that humanities, arts, and social science curricula are generally known for developing students' writing skills, it is additionally remarkable that the research students in the Senior Survey reported their writing abilities to be greater, on a statistically significant level, than those reported by the sample of nonresearch students in the same fields and with similar grades and demographic characteristics.

These student gains in critical thinking/problem solving, professionalism/work ethic, and oral/written communication correspond to three of the four most critical skill areas sought by employers, according to NACE (2019). Although the Senior Survey and entry/exit surveys reflect undergraduate students' self-reported gains, the authors' continue to investigate whether and how the undergraduate research experience in humanities, arts, and social science fields impacts alumni trajectories and careers after graduation.

Although this study finds these consistent correlative outcomes across the varied research experiences of under- 
TABLE 2. URC-HASS Entry and Exit Survey Data (URSP and URFP Participants 2014-2018)

\begin{tabular}{|c|c|c|c|}
\hline Self-reported proficiency ratings & $\begin{array}{l}\text { Pre-program } \\
\text { mean rating }\end{array}$ & $\begin{array}{l}\text { Post-program } \\
\text { mean rating }\end{array}$ & $\begin{array}{c}t \text {-statistic; significance } \\
\text { (1-tailed) }\end{array}$ \\
\hline Developing a research question (CT/PS) & 2.27 & 2.77 & $\begin{array}{l}-8.61 \\
<0.001\end{array}$ \\
\hline Finding sources (CT/PS) & 2.47 & 2.91 & $\begin{array}{l}-7.82 \\
<0.001\end{array}$ \\
\hline Conducting a literature review (CT/PS) & 2.07 & 2.59 & $\begin{array}{l}-7.99 \\
<0.001\end{array}$ \\
\hline Analyzing and synthesizing information (CT/PS) & 2.48 & 2.89 & $\begin{array}{l}-7.70 \\
<0.001\end{array}$ \\
\hline Developing an argument (CT/PS) & 2.53 & 2.89 & $\begin{array}{l}-6.55 \\
<0.001\end{array}$ \\
\hline Presenting my findings/arguments in writing (O/WC) & 2.38 & 2.86 & $\begin{array}{l}-8.53 \\
<0.001\end{array}$ \\
\hline Presenting my findings/arguments orally (O/WC) & 2.17 & 2.77 & $\begin{array}{l}-8.49 \\
<0.001\end{array}$ \\
\hline Writing a research proposal (O/WC) & 2.26 & 2.75 & $\begin{array}{l}-8.50 \\
<0.001\end{array}$ \\
\hline
\end{tabular}

Note: URC-HASS = UCLA's Undergraduate Research Center for the Humanities, Arts, and Social Sciences. CT/PS = critical thinking/problem solving. $\mathrm{O} / \mathrm{WC}=$ oral/written communication. Exact wording from entry/exit surveys: "Please rank your proficiency level for the following skills:" Scale: $0=$ None, 1 = Beginner, 2 = Intermediate, 3 = Advanced, $4=$ Expert. All findings significant at $p<0.001 . n=199$.

\section{TABLE 3. UCLA Senior Survey Data}

\begin{tabular}{|l|c|c|c|}
\hline Self-reported ratings & $\begin{array}{c}\text { URC-HASS student } \\
\text { mean rating }\end{array}$ & $\begin{array}{c}\text { Matched control group } \\
\text { student mean rating }\end{array}$ & $\begin{array}{c}t \text {-statistic; significance } \\
\text { (2-tailed) }\end{array}$ \\
\hline UCLA impact on academic and personal development & \multicolumn{2}{|c|}{} \\
\hline $\begin{array}{l}\text { Ability to make informed decisions that require analyz- } \\
\text { ing information from many perspectives (CT/PS) }\end{array}$ & 3.54 & 3.22 & $3.49 ;$ \\
\hline Critical thinking (CT/PS) & 3.60 & 3.28 & $\begin{array}{c}4.07 ; \\
p<0.001\end{array}$ \\
\hline Desire for lifelong learning (P/WE) & 3.55 & 3.32 & $2.48 ;$ \\
\hline Ability to communicate effectively in writing (O/WC) & 3.42 & 3.20 & $p=0.014$ \\
\hline
\end{tabular}

Note: URC-HASS = UCLA's Undergraduate Research Center for the Humanities, Arts, and Social Sciences. CT/PS = critical thinking/problem solving. $\mathrm{P} / \mathrm{WE}=$ professionalism/work ethic. $\mathrm{O} / \mathrm{WC}=$ oral/written communication. Exact wording from Senior Survey: "Please indicate to what extent your UCLA experience has contributed to your . .." [see items in column 1]. Scale: $1=$ None/Very Little, $2=$ Some, $3=$ Quite a Bit, $4=$ Very Much. All findings significant at $p<0.05 . n=298$.

\begin{tabular}{|l|c|c|c|}
\hline Self-reported ratings & $\begin{array}{c}\text { URC-HASS student } \\
\text { mean rating }\end{array}$ & $\begin{array}{c}\text { Matched control group } \\
\text { student mean rating }\end{array}$ & $\begin{array}{c}t \text {-statistic; significance } \\
\text { (2-tailed) }\end{array}$ \\
\hline Traits compared with average person of same age & 4.32 & 3.90 \\
\hline Academic ability (CT/PS) & $4.93 ; 0.001$ & $2.71 ;$ \\
\hline Drive to achieve (P/WE) & & 4.08 \\
\hline Writing ability (O/WC) & 4.20 & 3.96 \\
\hline
\end{tabular}

Note $:$ URC-HASS = UCLA's Undergraduate Research Center for the Humanities, Arts, and Social Sciences. CT/PS $=$ critical thinking/problem solving. $\mathrm{P} / \mathrm{WE}=$ professionalism/work ethic. $\mathrm{O} / \mathrm{WC}=$ oral/written communication. Exact wording from Senior Survey: "Rate yourself on each of the following traits as compared with the average person your age. We want the most accurate estimate of how you see yourself." Scale: $1=$ Lowest 10 percent, $2=$ Below Average, $3=$ Average, $4=$ Above Average, $5=$ Highest 10 percent. All findings significant at $p<0.05 . n=298$. 
graduates in the humanities, arts, and social sciences, it is still uncertain as to which aspects of the research experience specifically precipitate such outcomes. Moreover, the URC-HASS programs themselves may have provided crucial benefits beyond those available to student researchers outside of the program, including scholarship funding, camaraderie and peer support, additional guidance from URC-HASS program directors and graduate student staff, cross-disciplinary exposure to research across other fields, and validation of acceptance to the program. These benefits may have affected students' skills gained or personal attitudes toward the research experience. It is also reasonable to expect that different types of students need different types of resources to benefit most from research experiences, and thus the pool of supplemental resources available to students in the programs, and largely on an access-as-needed basis, provided crucial individualized support. Further study will need to investigate potential causal mechanisms while considering the diversity within student populations.

\section{Conclusion}

With relatively little research currently available on undergraduate research experiences and outcomes in the humanities, arts, and social sciences, this study elucidates several potential academic and professional gains. Additional work on undergraduate research experiences in the humanities, arts, and social sciences will lead to a more comprehensive picture and a basis for comparison against the outcomes for STEM students.

As they stand, these findings suggest that campuses should invest in more centralized support and resources, including opportunities for cross-disciplinary peer support, to aid student researchers in humanities, arts, and social science fields and to help offset variances across departments and faculty availability. Given that these results are based on student self-reported competencies, future research is also needed to examine whether such self-reported outcomes are demonstrable and how they affect students' trajectories after graduation. This is a topic under investigation by the authors.

Given these findings, campus leaders and student advisers (including career advisers) might re-evaluate the role of undergraduate research in preparing students for the workforce. Decision-making, critical thinking, and oral and written communication skills are precisely the skills and dispositions that employers have indicated are most needed but lacking in their recent graduate hires - including graduates with STEM skills and degrees (Chronicle of Higher Education 2012; NACE 2019). Although, in recent years, vocational value has often been attached to STEM fields and investments made in producing more STEM graduates, the results here suggest the importance of reaffirming and strengthening the core of academic scholarship and knowledge creation in the humanities, arts, and social sciences. Through research pursuits, undergraduates in those fields can gain valuable transferrable skills for today's labor market.

\section{References}

Chronicle of Higher Education. 2012. The Role of Higher Education in Career Development: Employer Perceptions. Washington, DC: Chronicle of Higher Education. Accessed May 10, 2021. https://chronicle-assets.s3.amazonaws.com/5/items/biz/ pdf/Employers\%20Survey.pdf

Craney, Chris, Tara McKay, April Mazzeo, Janet Morris, Cheryl Prigodich, and Robert de Groot. 2011. "CrossDiscipline Perceptions of the Undergraduate Research Experience." Journal of Higher Education 82(1): 92-113. doi: 10.1080/00221546.2011.11779086

DeAngelo, Linda, and Tama Hasson. 2009. "Quantifying Success: Using Control Groups to Measure Program Effectiveness." CUR Quarterly 29(3): 39-45.

Haeger, Heather, John E. Banks, Camille Smith, and Monique Armstrong-Land. 2020. "What We Know and What We Need to Know about Undergraduate Research." Scholarship and Practice of Undergraduate Research 3(4): 62-69. doi: 10.18833/ spur/3/4/4

Hartmann, David J. 1990. "Undergraduate Research Experience as Preparation for Graduate School." American Sociologist 21: 179-188. doi: 10.1007/BF02692860

Hayot, Eric. May 2018. "The Sky Is Falling." Profession. Accessed May 10, 2021. https://profession.mla.org/the-sky-isfalling/

Ishiyama, John. 2002. "Does Early Participation in Undergraduate Research Benefit Social Science and Humanities Students?" College Student Journal 36: 380-386.

Kremer, John F., and Robert G. Bringle. 1990. "The Effects of an Intensive Research Experience on the Careers of Talented Undergraduates." Journal of Research and Development in Education 24(1): $1-5$.

Landrum, R. Eric, and Lisa R. Nelsen. 2002. "The Undergraduate Research Assistantship: An Analysis of the Benefits." Teaching of Psychology 29(1): 15-19. doi: 10.1207/ s15328023top2901_04

Lopatto, David. 2006. "Undergraduate Research as a Catalyst for Liberal Learning." Peer Review 8(1): 22-25.

National Association of Colleges and Employers (NACE). 2019. Job Outlook 2019. Bethlehem, PA: National Association of Colleges and Employers.

Nnadozie, Emmanuel, John Ishiyama, and Jane Chon. 2001. "Undergraduate Research Internships and Graduate School Success." Journal of College Student Development 42: 145-156.

Prenovitz, Sarah J., Gary R. Cohen, Ronald G. Ehrenberg, and George H. Jakubson. 2016. "An Evaluation of the Mellon Mays Undergraduate Fellowship's Effect on PhD Production at Non-UNCF Institutions." Economics of Education Review 53: 284-295. doi: 10.1016/j.econedurev.2016.04.005 
Rand, Jane. 2016. "Researching Undergraduate Social Science Research." Teaching in Higher Education 21: 773-789. doi: 10.1080/13562517.2016.1183621

Toven-Lindsey, Brit, Marc Levis-Fitzgerald, Paul H. Barber, and Tama Hasson. 2015. "Increasing Persistence in Undergraduate Science Majors: A Model for Institutional Support of Underrepresented Students." CBE-Life Sciences Education 14(2): 1-12. doi: 10.1187/cbe.14-05-0082

\section{Kelly Kistner}

University of California, Los Angeles,

kkistner@college.ucla.edu

Kelly Kistner is an assistant director of the Undergraduate Research Center for the Humanities, Arts, and Social Sciences at the University of California, Los Angeles (UCLA). She oversees various undergraduate research programs and teaches in the Honors Collegium. She received her $P h D$ in sociology from the University of Washington and is broadly interested the history of higher education and the sociology of knowledge production.

Erin M. Sparck is a postdoctoral researcher at UCLA. She received her PhD in psychology from UCLA studying the application of cognitive psychology to education. She currently works in the Center for Educational Assessment (CEA) housed within the Center for the Advancement of Teaching (CAT). Current projects at CEA include the development and implementation of assessment strategies for various campus programs and research on improving the quality of instruction and student learning.

Amy Liu is a researcher with the Center for Educational Assessment and lecturer in the Graduate School of Education \& Information Studies at UCLA.

Hannah Whang Sayson is assistant director of data analytics at the UCLA Center for Educational Assessment.

Marc Levis-Fitzgerald is director of the UCLA Center for Educational Assessment. He leads campus efforts designed to understand the impact of curriculum reform. In this capacity, he oversees campus quarterly course evaluation; implements curriculum assessment at the course, program, and department levels; provides internal and external grant-funded assessment; guides campus survey research that includes directing UCLA's ongoing graduating senior survey; and oversees transfer partnership review.

Whitney Arnold is director of the Undergraduate Research Center for the Humanities, Arts, and Social Sciences and adjunct assistant professor of comparative literature and medicine at UCLA. In addition to overseeing the Undergraduate Research Center, she mentors undergraduate researchers and teaches research-based courses in comparative literature and medicine. She studies undergraduate research outcomes in humanities, arts, and social science fields and works more broadly on teaching and mentoring initiatives across campus.

\section{Want to Review Manuscripts for SPUR?}

Send an email to SPUR@cur.org indicating areas of interest/specialization (e.g., assessment). Experience with qualitative/quantitative methods is highly desired. 